\title{
Adolescent Dating Violence Victimization and Psychological Well-Being
}

\author{
Michelle R. Callahan \\ Richard M. Tolman \\ Daniel G. Saunders \\ University of Michigan
}

\begin{abstract}
This study assesses the relationship between adolescents' dating violence victimization and their psychological well-being. The participants were 190 high school students, ages 13 to 19 years, with just over half being boys (53\%) and the remainder being girls (47\%). Data were collected using self-administered questionnaires. For girls, increasing levels of dating violence (severity, frequency, injury) were related to higher levels of posttraumatic stress and dissociation, even after controlling for demographic, family violence, and social desirability variables. For boys, the levels of victimization were related to higher levels of anxiety, depression, and posttraumatic stress, even after controlling for other variables. For both boys and girls, victimization was related to lower levels of life satisfaction, but not after controlling for the demographic, family violence, and social desirability variables. The research questions and findings are discussed in relation to the developmental challenges faced by adolescents.
\end{abstract}

Keywords: dating; violence; psychological; well-being; adolescent

About a third of students in Grades 9 through 12 report experiencing some form of physical abuse in a casual or serious dating relationship (Avery-Leaf, Cascardi, O’Leary, \& Cano, 1997; Jezl, Molidor, \& Wright, 1996; Malik, Sorenson, \& Aneshensel, 1997; Molidor \& Tolman, 1998; Reuterman \& Burcky, 1989), and victims experience both physical and psychological harm (Burcky, Reuterman, \& Kopsky, 1988; Foshee, 1996; Henton, Cate, Koval,

This study is based on portions of a doctoral dissertation completed by Michelle R. Callahan in the Department of Psychology at the University of Michigan. Portions of this work were presented at the Biennial Meeting of the Society for Research in Child Development in Albuquerque, New Mexico, April 1999. The Office of the Vice President of Research and the Horace H. Rackham Graduate School at the University of Michigan supported this research. Correspondence concerning this article should be addressed to Michelle R. Callahan, 58 Cottonwood Street, Jersey City, NJ 07305.

Journal of Adolescent Research, Vol. 18 No. 6, November 2003 664-681 DOI: $10.1177 / 0743558403254784$

(C) 2003 Sage Publications

664 
Lloyd, \& Christopher, 1983; Jezl et al., 1996; Molidor \& Tolman, 1998). It is critical to explore the impact of dating violence on adolescent psychological well-being because adolescents are progressing through a developmental stage that may place them at even greater risk than adults for physical and psychological harm. Given their lack of experience, reliance on support and advice from inexperienced peers, and their quest for autonomy, adolescents usually have fewer resources in responding to violence. As relationships become more serious, less group dating occurs and couples spend more time in isolation, which can also be a risk factor. Adolescents often have difficulty identifying physical and sexual abuse as such and deciding how to respond to it. They may even falsely perceive controlling and jealous behavior as love (Levy, 1990).

Some developmental theories suggest that girls form identities through relationships, whereas boys form identities through independence (Chodorow, 1978; Miller, 1991). Therefore, a female's self-concept and self-esteem may be closely related to how she is treated in her dating relationship. This suggests that dating violence may have more impact on girls than on boys.

Few studies have examined the effects of dating violence using standardized measures of psychological well-being. Some studies have asked respondents to indicate their feelings about violence. For example, Henton and her colleagues (1983) found that victims most frequently said they felt angry $(60.3 \%)$, hurt $(57.5 \%)$, surprised or sorry $(34.2 \%$ each), or scared $(31.5 \%)$. Twelve percent of female adolescents in one study (Burcky et al., 1988) said the incident had no particular effect on their emotional state and $56 \%$ said the incident upset them, but that it did not cause any major trauma or long-term effects. Eight percent reported substantial trauma and were disturbed about the incident for a long time. The degree to which one feels physical and emotional harm as a result of the violence is likely to be related to poorer psychological well-being outcomes. Thus, severity of physical harm is likely to be related to lower psychological well-being (O'Leary, 1999).

Many studies have found that female adolescents report higher rates of dating violence victimization and perpetration than do male adolescents (e.g., Bergman, 1992; O'Keefe, Brockopp, \& Chew, 1986; Roscoe \& Callahan, 1985; Roscoe \& Kelsey, 1986). Girls also report experiencing significantly more severe and higher rates of sexual victimization than do boys (Bergman, 1992; Foshee, 1996; Molidor \& Tolman, 1998), and more injuries and more severe injuries (Foshee, 1996; Molidor \& Tolman, 1998). In addition, girls are more likely to report defending themselves against partner assaults (Foshee, 1996; Molidor \& Tolman, 1998). Molidor and Tolman (1998) found that when examining the worst incident of dating violence experienced in their dating relationship, boys reported that the violence had no effect ("did not hurt at 
all") or a minimal effect ("hurt me a little") in over $90 \%$ of the violent incidents. In sharp contrast, girls reported that they experienced serious harm ("hurt me a lot") in $47.8 \%$ of the incidents, with physical injury ("caused bruises," "needed medical attention") in $33.6 \%$ of the incidents. This research suggests that girls are at even greater risk than are boys for self-reported physical and emotional harm.

Several psychological sequelae of adolescent dating violence are likely to occur. Although posttraumatic stress has not been investigated in adolescent victims of dating violence, adolescents exposed to violence both within their homes and in the community experience posttraumatic stress symptoms; girls report more symptomology than boys (Fitzpatrick \& Boldizar, 1993). Among adult female victims of domestic violence, posttraumatic symptomology is common (e.g. Campbell \& Lewandowski, 1997).

Dissociation is another traumatic response that has not received attention in research on adolescent dating violence, but it could very likely occur. Dissociation is most often investigated in samples of severely battered women, and dissociative symptoms such as shock, denial, withdrawal, confusion, and psychological numbing are common (Dutton, 1992).

Lowered self-esteem is another likely sequela of dating violence. Adult victims of dating violence have lower self-esteem than do nonvictims (Burke, Stets, \& Pirog-Good, 1989; Deal \& Wampler, 1986; Orava, McLeod, \& Sharpe, 1996; Stets \& Pirog-Good, 1987). Jezl et al. (1996) found that girls who remained in physically abusive relationships had significantly lower self-esteem than did boys. According to Gallers and Lawrence (1991), adolescent date rape can result in damage to the self-image. The frequency of violence is negatively related to self-esteem among battered women (Mitchell \& Hodson, 1983).

Life satisfaction is considered a cognitive component of subjective wellbeing. It measures an individual's subjective summation (as opposed to the actual condition) of the quality of life (Andrews \& Withey, 1976; Campbell, 1981; Campbell, Converse, \& Rodgers, 1976). Life satisfaction has not been explored in the research on interpersonal violence. However, we expect dating violence to negatively impact life satisfaction.

Depression and anxiety also have not been adequately explored as sequelae of adolescent dating violence. Among adults, depression has been associated with greater frequency and severity of abuse (Campbell \& Lewandowski, 1997; Cascardi \& O'Leary, 1992; Mitchell \& Hodson, 1983; Orava et al., 1996). A study of college students found that female victims of dating violence were significantly more likely to report experiencing fear and anxiety than were males (Follingstad, Wright, Lloyd, \& Sebastian, 1991). 
We predict that increased severity and frequency of dating violence and the occurrence of physical injuries will be negatively related to psychological well-being (higher self-esteem and life satisfaction, and lower posttraumatic stress, dissociation, and depression). We also predict that these relationships will hold after controlling for demographic variables (age, race, socioeconomic status), experiences with family violence in childhood (both witnessing domestic violence and child abuse), and social desirability response bias.

\section{METHOD}

\section{Participants}

The sample was from a high school in southern Michigan with approximately 526 students from predominantly lower- to middle-class families. Within this school, $65 \%$ of the students scored below average in reading and math. Permission slips describing the purpose and goals of this study and requesting the active consent of a parent were mailed to the adolescents' homes and distributed to the students in the school. Data were collected from 224 students. Eighteen were omitted from the analyses because they did not indicate that they had any dating experience. Of the remaining 206 respondents, 6 were omitted for a lack of information about race and/or gender. Given the small numbers of other racial groups, 10 respondents who were neither Black nor White were dropped from the analyses (for more information on the methods, see Callahan, 1998).

Therefore, the final sample for analysis includes 190 high school students. Of the 100 boys, $50 \%$ were Black and 50\% were White. Of the 90 girls, $51 \%$ were Black and $49 \%$ were White. The focus of the analysis in this study is on gender differences. The students' ages ranged from 13 to 19 years, with a mean of 15.9 years $(S D=1.29)$, with the following distribution: $1 \%$ age 13 ; $15 \%$ age $14 ; 27 \%$ age $15 ; 26 \%$ age $16 ; 20 \%$ age $17 ; 9 \%$ age 18 ; and $1 \%$ age 19. Forty-one percent of the sample received free lunch in school. Within this sample of adolescents, $45.7 \%$ reported ever being a victim of dating violence, $51.6 \%$ reported ever being a perpetrator of dating violence, and $61.7 \%$ reported some experience with dating violence either as a victim, a perpetrator, or both. Participants received a $\$ 5$ payment for completing the selfadministered questionnaire. 


\section{Measures}

\section{Demographic Measures}

Participants indicated their age, race, gender, and socioeconomic status. Adolescents' socioeconomic status was determined by their response to the item "Do you get free lunch at school?" Receiving free lunch was used as an indicator of low-income status.

\section{Violence Measures}

Dating violence victimization was measured using a modified version of the Conflict Tactics Scale-2 (CTS2) (Straus, Hamby, Boney-McCoy, \& Sugarman, 1996), designed to assess interpersonal violence, including dating violence (Straus, 1990b).

Items from the Physical Assault and Sexual Coercion subscales were selected from the five CTS2 subscales. Ten of the 12 items from the Physical Assault scale were utilized in their original form. Some revisions were made in attempts to use items most appropriate for an adolescent sample. The following item was added: "My partner threatened to hit or throw something at me." The item "My partner burned or scalded me" was omitted. The item "My partner used a knife or gun on me" was changed to "My partner threatened to use or used a knife or gun on me." Two sexual coercion items were utilized: "My partner used threats to make me have sex" and "My partner used force (like hitting, holding down, or using a weapon) to make me have sex." Before the completion of the 14 violence items, the participants were given the following instructions:

Have any of your boyfriends/girlfriends ever DONE any of the following TO YOU in a dating relationship? Circle "no" or "yes." How often in the past 12 months? Circle the best answer: 0 times, 1 time, 2-5 times, more than 5 times.

Adding the frequencies of all of the items created a frequency scale. We used the midpoint of 2 to 5 times (3.5) and kept the other codes the same as the above response format. The scale ranged from 0 to 70 and was highly skewed, with $63 \%$ of the sample reporting no victimization. To reduce the skewedness, we partitioned the scale into three groups: 0 times $(n=108) ; 1$ to 6 times $(n=35)$; and 7 to 70 times $(n=33)$.

We utilized Straus et al.'s (1996) severity distinctions to create scales: mild violence victimization (the six mild items from the Physical Assault scale) and severe violence victimization (the remaining six severe items from 
the Physical Assault scale plus the two items from the Sexual Coercion scale). This distinction has been commonly used in other research (Gelles, 1991; Holtzworth-Munroe \& Stuart, 1994; Johnson, 1995; Straus, 1990a; Straus et al., 1996) but has not been validated. The Cronbach's alphas for this sample were .81 for mild violence and .80 for severe violence.

Respondents were asked about the occurrence of major injuries and minor injuries, and scratches and bruises. Because there were very few injuries other than scratches and bruises reported, all injuries were treated the same and an injury variable was created and coded by frequency. Injury was coded as none, one, or two injuries.

Violence in the family of origin is linked not only to poor psychological well-being outcomes for adolescents but also to experience with dating violence. Witnessing domestic violence or experiencing child abuse is related to significant emotional and behavioral problems in children and adolescents, including posttraumatic stress disorder symptomology, anxiety, dissociation, stress, depression, aggression, and delinquency (Boney-McCoy \& Finkelhor; 1995, Graham-Bermann, 1998; Graham-Bermann \& Levendosky, 1998; O'Keefe et al., 1986; Singer, Anglin, Song, \& Lunghofer, 1995). The adolescents' experiences with violence in the family of origin were assessed with a condensed version of the CTS. We created a four-item behavior checklist by taking all of the theoretically nonsevere violence items (i.e., push, grab, shove, slap, throw an object, or kick) and combining them into one item and then taking all of the severe violence items (i.e., beat up, choke or strangle, or threaten with or use a knife or a gun) and combining them into a second item. This broad definition probably led to the relatively high frequencies of child abuse in this sample. The respondents were asked to indicate how frequently their fathers (stepfather, mom's boyfriend) and mothers (stepmother, dad's girlfriend) were aggressive toward one another. Two items each assessed the father's mild and severe aggression toward the mother and the mother's aggression toward the father. The respondents gave the frequency of each item with the following: "never," "once or twice," "310 times," "11-50 times," and "over 50 times." We created a similar measure of adolescents' experiences with child abuse. This checklist included two items each for father-to-child violence and mother-to-child violence. The items read: (a) "How often did each family member do any of the following to you: push, grab shove, slap, throw an object, or kick you?" and, (b) "How often did each family member do any of the following to you: beat you up, choke or strangle you, or threaten you with or use a knife or gun on you? (never, once or twice, 3-10 times, 11-50 times, and over 50 times)." 


\section{Psychological Well-Being Measures}

Adolescent anxiety was measured with a 10-item short form of the Trait scale (Form A) of the Spielberger State-Trait Anxiety Inventory, Form X (Devito \& Kubis, 1983; Spielberger, Gorusch, \& Lushene, 1970). The Trait Anxiety (A-Trait) scale measures anxiety proneness, a relatively stable personality characteristic (Devito \& Kubis, 1983). The Cronbach's alpha calculated for this sample was .79.

Adolescent depression was measured with the 10-item Children's Depression Inventory Short Form (Kovacs, 1992). This 10-item scale assesses the adolescents' self-reported depressive symptoms. For each item, participants are asked to select one of the three statements that best describes the way that the participant has been feeling during the past 2 weeks. For each item, scores are $0=$ absence of symptom, $1=$ mild symptom, and $2=$ definite symptom. The short form of the Children's Depression Inventory correlates $r=.89$ with the full version, and the reported Cronbach's alpha coefficient ranges from .71 to .89 (Kovacs, 1992). The Cronbach's alpha calculated for this sample was .83.

The Rosenberg Self-Esteem Scale (1965) measured self-esteem. Adolescents rated agreement with 10 statements (e.g., "I feel that I have a number of good qualities") using a 4-point Likert-type scale (1 = strongly agree, 2 = agree, 3 = disagree, $4=$ strongly disagree $)$. The Cronbach's alpha calculated for this sample was .83 .

Adolescent life satisfaction was measured with the item "How satisfied are you with your life as a whole these days?" on a 7-point Lykert-type scale with the following anchor points: $1=$ completely satisfied, $4=$ neutral, and 7 = completely dissatisfied . Satisfaction in seven additional domains of life (self, family life, romantic relationship[s], family income, friendships, school and neighborhood/community) was measured using the same response set with the items "How satisfied are you with ___ these days?" These eight items were combined to form a measure of global life satisfaction (alpha $=.76$ for this sample). These domains were selected from 12 domains of life satisfaction outlined by Campbell (1981) because they appeared to be the most applicable to adolescents.

The adolescents' traumatic symptomology was measured by the Trauma Symptom Checklist for Children (TSCC) (Briere, 1996). The TSCC is designed to evaluate children's responses to unspecified traumatic events in many different symptom domains (Briere, 1996). Items from the Posttraumatic Stress and Dissociation subscales were selected from the six TSCC subscales. The 10-item dissociation scale measures mild-to-moderate dissociative symptomology (Briere, 1996). From the Posttraumatic Stress scale, only 8 of the 10 items were utilized. The items "feeling scared of men" and 
"feeling scared of women" were omitted from the Posttraumatic Stress scale due to their ambiguous meaning and unusual wording for this age group. The Cronbach's alphas calculated for this sample were .84 for posttraumatic stress and .78 for dissociation.

\section{Social Desirability Response Bias}

The validity of self-report is lowered by social desirability response bias (Arias \& Beach, 1987). Research suggests that reports of victimization are generally unbiased (Arias \& Beach, 1987) and that males may be more susceptible to social desirability response bias (Arias \& Johnson, 1989). Social desirability response bias was measured with a 10 -item version of the Marlowe-Crowne Social Desirability Scale that was then used as a covariate (Crowne \& Marlowe, 1964; Greenwald \& Satow, 1970; Saunders, 1991). The Cronbach's alpha calculated for this sample was .66.

\section{Data Analyses Plan}

The relationships between dating violence (severity, frequency, and injuries) and psychological well-being were examined. It was hypothesized that more severe, frequent, and injurious victimization would be significantly and positively related to anxiety, depression, dissociation, and posttraumatic stress, and significantly and negatively related to life satisfaction and selfesteem. We conducted correlational and hierarchical regression analyses.

\section{RESULTS}

\section{Descriptive and Bivariate Results}

Descriptive statistics. Descriptive analyses (see Table 1) revealed several gender differences. Girls reported experiencing significantly more severe and frequent dating violence victimization and witnessing of parental domestic violence than did boys. Girls also reported significantly higher scores on social desirability response bias and anxiety. Boys reported significantly higher scores on life satisfaction and receiving free lunch.

When comparing victimized girls and boys, there were fewer significant differences. Victimized girls scored higher than boys did on social desirability response bias and posttraumatic stress. Victimized boys were more likely than victimized girls to be enrolled in the school lunch program. 
TABLE 1: Means, Standard Deviations, and Chi-Squares of Major Study Variables for Boys and Girls by Status of Victimization

\begin{tabular}{|c|c|c|c|c|c|c|c|c|}
\hline & \multicolumn{4}{|c|}{ Total Sample } & \multicolumn{4}{|c|}{ Victim Sample } \\
\hline & \multicolumn{3}{|c|}{ Mean (SD) } & \multirow[b]{2}{*}{ t Value } & \multicolumn{3}{|c|}{ Mean (SD) } & \multirow[b]{2}{*}{ t Value } \\
\hline & \multicolumn{2}{|c|}{$\begin{array}{c}\text { Girls } \\
(\mathrm{n}=90)\end{array}$} & $\begin{array}{c}\text { Boys } \\
(\mathrm{n}=100)\end{array}$ & & $\begin{array}{l}\text { Girls } \\
(\mathrm{n}=50)\end{array}$ & \multicolumn{2}{|c|}{$\begin{array}{l}\text { Boys } \\
(\mathrm{n}=36)\end{array}$} & \\
\hline Age & 15.7( & 1.2) & $16.0(1.4)$ & 1.42 & $15.8(1$. & 2) 16.2 & $(1.3)$ & 1.47 \\
\hline Marlowe-Crowne & 4.5( & $0.9)$ & $4.2(0.7)$ & $2.24^{*}$ & $4.5(0$. & & $(0.5)$ & $2.54^{*}$ \\
\hline Anxiety & 2.1 & $0.5)$ & $1.9(0.05)$ & $-3.30^{* *}$ & $2.1(0$. & & $(0.5)$ & 1.2 \\
\hline Depression & 0.6( & $0.2)$ & $0.6(0.2)$ & 0.3 & $0.6(0$. & & $(0.2)$ & -0.1 \\
\hline Dissociation & 1.0( & $0.5)$ & $0.9(0.5)$ & 1.3 & $1.0(0$. & & $(0.5)$ & 0.8 \\
\hline Life satisfaction & 4.9( & $0.8)$ & $5.2(1.0)$ & $2.07^{*}$ & $4.8(0$. & & $(1.1)$ & -0.4 \\
\hline Posttraumatic stress & 1.2( & $0.6)$ & $1.0(0.6)$ & $-2.4^{*}$ & $1.4(0$. & & $(0.6)$ & $2.6^{* *}$ \\
\hline \multirow[t]{4}{*}{ Self-esteem } & 3.1( & $0.5)$ & $3.2(0.5)$ & -1.0 & $3.1(0$. & & (0.4) & 0.0 \\
\hline & & \multicolumn{3}{|c|}{ Total Sample } & \multicolumn{4}{|c|}{ Victim Sample } \\
\hline & & \multicolumn{2}{|c|}{ Percentages } & & \multicolumn{2}{|c|}{ Percentages } & \multirow{2}{*}{\multicolumn{2}{|c|}{ Chi-Square }} \\
\hline & & Girls & Boys $\mathrm{C}$ & Chi-Square & Girls & Boys & & \\
\hline \multicolumn{2}{|c|}{ Black/African American } & 54 & 52 & 0.1 & 54 & 58 & & 0.1 \\
\hline \multicolumn{2}{|c|}{ School lunch } & 32 & 50 & $6.2^{* *}$ & 36 & 61 & & $5.3^{*}$ \\
\hline \multicolumn{2}{|l|}{ Child abuse } & 57 & 55 & 0.0 & 62 & 72 & & 0.8 \\
\hline \multicolumn{9}{|l|}{ Witnessed domestic } \\
\hline \multicolumn{2}{|l|}{ violence } & & & $8.3^{*}$ & & & & \\
\hline \multicolumn{2}{|l|}{ No victimization } & 43 & 64 & & NA & NA & & \\
\hline \multicolumn{2}{|l|}{ Mild victimization } & 18 & 13 & & 30 & 36 & & 0.2 \\
\hline \multicolumn{2}{|l|}{ Severe victimization } & 39 & 23 & & 70 & 64 & & 0.2 \\
\hline \multicolumn{2}{|l|}{ Injury } & & & 2.9 & & & & 2.5 \\
\hline \multicolumn{2}{|l|}{ No injury } & 78 & 83 & & 58 & 56 & & \\
\hline \multicolumn{2}{|l|}{ One injury } & 19 & 11 & & 32 & 29 & & \\
\hline \multicolumn{2}{|l|}{ Two injuries } & 3 & 6 & & 9 & 15 & & \\
\hline Frequency of violence & & & & $9.7^{\star \star \star}$ & & & & 0.7 \\
\hline None in past year & & 46 & 68 & & 4 & 3 & & \\
\hline 1 to 6 times in past & year & 32 & 16 & & 54 & 46 & & \\
\hline 7 to 70 times in pas & t year & 22 & 17 & & 42 & 51 & & \\
\hline
\end{tabular}

NOTE: NA = not applicable. The sample size for the above statistics ranged from 83 to 90 for girls and 92 to 100 for boys.

${ }^{*} p<.05 .{ }^{* *} p<.01 .{ }^{* * *} p<.001$.

Table 2 shows the correlations between dating violence victimization and the measures of psychological well-being. For the girls, there were positive and significant correlations between the three measures of dating violence 
and reports of posttraumatic stress (see Table 2). In addition, more severe violence was significantly related to lower life satisfaction. There were no significant correlations with the other four measures of psychological wellbeing: dissociation, depression, anxiety, and self-esteem. For the boys, there were positive and significant correlations between violence severity and injury and the measure of anxiety (see Table 2). In addition, all three measures of dating violence were related to lower levels of life satisfaction. There were no significant correlations with the other four measures of psychological well-being: dissociation, depression, posttraumatic stress, and self-esteem. Therefore, some of the measures of psychological well-being for both boys and girls were correlated with at least one measure of victimization.

\section{Hierarchical Regression Results}

Step one included the demographic variables age, race (Black $=1$ and White $=0$ ), socioeconomic status (as measured by whether or not the participant receives free school lunch, yes $=1$ and no $=0$ ), and social desirability response bias. Step two added the family-of-origin violence variables: witnessed domestic violence (yes $=1$ and no $=0$ ) and experienced child abuse (yes $=1$ and no $=0$ ). Step three added the dating violence variables: severity of victimization (no violence $=0$, mild dating violence $=1$, any severe dating violence $=2$ ), frequency of victimization (no violence in the last 12 months = 0,1 to 6 times $=1,7$ to 70 times $=2$ ), and occurrence of injuries (no injuries $=$ 0 , one injury $=1$, two injuries $=2$ ). Violence in the family of origin was entered before dating violence because temporally it is most likely to be experienced before dating, and it is hypothesized to have a negative effect on psychological well-being. Separate regressions were run for depression, anxiety, posttraumatic stress, dissociation, self-esteem, and life satisfaction.

Table 3 shows the combined impact of the three measures of dating violence when controlling for demographic variables (age, race, receiving free school lunch), social desirability response bias, and family-of-origin violence. For girls, the relationship between victimization and posttraumatic stress held even when controlling for demographics, family-of-origin violence, and social desirability response bias. The results indicate that for girls, victimization was significantly related to posttraumatic stress (see Table 3 ). The addition of the three dating violence variables to the model resulted in a significant change in $R^{2}$ of $11 \%(p<.05)$.

A significant relationship between dating violence and dissociation emerged for girls (see Table 3 ). The addition of the three dating violence variables to the model resulted in a significant change in $R^{2}$ of $8 \%(p<.05)$. Although the relationship between dating violence and life satisfaction was 
TABLE 2: Correlation Matrix for Study Variables-Boys Below the Diagonal and Girls Above the Diagonal

\begin{tabular}{|c|c|c|c|c|c|c|c|c|c|c|c|c|c|c|c|}
\hline Variable & 1 & 2 & 3 & 4 & 5 & 6 & 7 & 8 & 9 & 10 & 11 & 12 & 13 & 14 & 15 \\
\hline 1. Age & - & .10 & -.05 & .14 & .10 & .09 & .05 & .05 & -.05 & .05 & .00 & -.13 & -.10 & $.27^{* *}$ & -.04 \\
\hline 2. Race $($ Black $=1)$ & -.14 & - & $.25^{\star}$ & .09 & -.12 & -.03 & -.10 & .04 & -.07 & -.01 & -.07 & $-.31^{\star \star}$ & $-.25^{*}$ & $.27^{\star *}$ & $.27^{\star \star}$ \\
\hline 3. Free lunch $($ yes $=1)$ & -.02 & $.32^{\star * *}$ & * & 11 & -.17 & 11 & -.02 & .09 & -.11 & -.05 & -.11 & -.13 & -.02 & .03 & -.03 \\
\hline 4. Social desirability & -.13 & .02 & .02 & - & -.09 & .10 & -.08 & -.09 & -.09 & $-.48^{\star * *}$ & $-.25^{*}$ & $-.22^{*}$ & $-.40^{\star \star *}$ & $.31^{* *}$ & $.26^{*}$ \\
\hline 5. Child abuse & 17 & $-.23^{\star}$ & -.07 & -.13 & - & $.30^{* * *}$ & .11 & .09 & .05 & $.27^{*}$ & $.33^{* *}$ & .09 & .20 & -.15 & -.21 \\
\hline 6. Domestic violence & .13 & $-.24^{\star}$ & -.03 & -.19 & $.38^{\star * *}$ & - & .05 & .12 & -.06 & .04 & 14 & .18 & .16 & -.19 & $-.31^{* *}$ \\
\hline 7. Severity of victimization & .07 & .15 & .16 & -.11 & $.24^{*}$ & .10 & - & $.85^{* * *}$ & $.59^{\star \star \star}$ & .08 & $.35^{\star *}$ & .08 & .09 & -.18 & $-.23^{\star *}$ \\
\hline 8. Frequency of & & & & & & & & & & & & & & & \\
\hline victimization & .13 & .00 & .07 & -.10 & $.30^{\star \star}$ & .16 & $.86^{\star \star \star}$ & - & $.67^{\star \star \star}$ & -.03 & .26 & .01 & -.01 & -.05 & -.14 \\
\hline 9. Victimization injuries & -.07 & -.04 & .06 & -.15 & $.25^{\star}$ & .16 & $.64^{\star \star *}$ & $.63^{\star \star \star}$ & - & .07 & $.24^{*}$ & .06 & .09 & -.07 & -.02 \\
\hline 10. Dissociation & .04 & $-.23^{\star}$ & $-.21^{*}$ & $-.27^{\star *}$ & .15 & .13 & .02 & -.01 & .12 & - & $.62^{\star \star *}$ & ${ }^{*} .30^{* \star *}$ & ${ }^{\star} .52^{\star \star \star}$ & $-.39^{\star \star \star}$ & ${ }^{\star}-.28^{\star \star}$ \\
\hline 11. Posttraumatic stress & -.01 & -.10 & -.13 & -.19 & .17 & .13 & .05 & -.05 & .18 & $.59^{\star * *}$ & - & $.37^{\star \star *}$ & ${ }^{*} .61^{* \star *}$ & $-.42^{\star \star \star}$ & ${ }^{\star}-.34^{\star \star *}$ \\
\hline 12. Depression & .18 & $-.21^{*}$ & .00 & $-.28^{* *}$ & .15 & .14 & .08 & -.01 & .18 & $.56^{\star * *}$ & $.47^{* * *}$ & - & $.50^{* * *}$ & $-.58^{* * *}$ & ${ }^{*}-.48^{* * *}$ \\
\hline 13. Anxiety & 11 & -.06 & 11 & $-.22^{*}$ & .05 & .09 & $.22^{*}$ & .12 & $.37^{* * *}$ & $.40^{* * *}$ & $.47^{\star * *}$ & $.68^{\star * *}$ & - & $-.69^{\star \star \star}$ & $\star-.47^{\star * *}$ \\
\hline 14. Self-esteem & -.10 & .16 & -.19 & $.23^{*}$ & -.06 & -.07 & -.16 & -.08 & -.16 & $-.35^{\star * *}$ & $-.29^{* *}$ & $-.66^{\star * *}$ & ${ }^{*}-.62^{\star * *}$ & - & $.43^{\star * *}$ \\
\hline 15. Life satisfaction & $-.36^{\star \star \star}$ & .05 & -.10 & $.29^{* *}$ & -.04 & $-.33^{*}$ & $-.21^{*}$ & $-.21^{*}$ & $-.20^{*}$ & $-.34^{* * *}$ & $-.30^{* *}$ & $-.62^{* * *}$ & ${ }^{\star}-.46^{\star \star \star}$ & $.48^{* * *}$ & - \\
\hline
\end{tabular}

NOTE: The sample size ranges from 92 to 100

${ }^{*} p<.05 .{ }^{* *} p<.01 .{ }^{* * *} p<.001$. 
TABLE 3: Hierarchical Regression for the Demographic, Social Desirability, and Interpersonal Violence Predictors of Well-Being

\begin{tabular}{|c|c|c|c|c|c|c|c|c|c|c|c|c|c|c|c|}
\hline & \multicolumn{3}{|c|}{ Anxiety: Boys } & \multicolumn{3}{|c|}{ Depression: Boys } & \multicolumn{3}{|c|}{$\begin{array}{c}\text { Posttraumatic } \\
\text { Stress: Boys }\end{array}$} & \multicolumn{3}{|c|}{$\begin{array}{c}\text { Posttraumatic } \\
\text { Stress: Girls }\end{array}$} & \multicolumn{3}{|c|}{ Dissociation: Girls } \\
\hline & Step 1 & 1 Step 2 & Step 3 & Step 1 & Step 2 & 2 Step 3 & 3 Step 1 & Step 2 & 2 Step 3 & 3 Step 1 & 1 Step 2 & Step 3 & Step 1 & Step 2 & Step 3 \\
\hline Age & .07 & .07 & .16 & .12 & .11 & .17 & -.04 & -.06 & .00 & .04 & -.00 & -.01 & .12 & .09 & .10 \\
\hline Black & -.10 & -.09 & -.12 & -.21 & -.19 & $-.23^{*}$ & -.06 & -.03 & -.06 & -.03 & -.00 & .05 & .03 & .05 & .11 \\
\hline Free lunch & .15 & .15 & .11 & .07 & .07 & .05 & -.10 & -.11 & -.13 & -.07 & -.05 & -.03 & .00 & .03 & .10 \\
\hline Social desirability & $-.22^{*}$ & $-.21^{*}$ & -.15 & $-.26^{*}$ & $-.25^{\star}$ & $-.22^{*}$ & -.19 & -.17 & -.14 & $-.25^{\star}$ & $-.23^{*}$ & $-.22^{*}$ & $-.50^{\star *}$ & $-.49^{\star \star \star}$ & ${ }^{*}-.51^{* *}$ \\
\hline Child Abuse & & -.01 & -.07 & & .06 & .05 & & .13 & .13 & & $.27^{\star}$ & $.24^{\star}$ & & $.22^{*}$ & $.22^{*}$ \\
\hline \multicolumn{16}{|l|}{ Witnessed domestic } \\
\hline violence & & .03 & .02 & & .01 & .02 & & .05 & .06 & & .08 & .11 & & .02 & .08 \\
\hline Severity of victimization & & & .30 & & & .40 & & & .37 & & & $.46^{*}$ & & & $.44^{*}$ \\
\hline Frequency of victimization & & & $-.45^{\star}$ & & & $-.57^{\star *}$ & & & $-.58^{\star *}$ & & & -.26 & & & $-.63^{\star \star}$ \\
\hline Injury & & & $.46^{* *}$ & & & .22 & & & .24 & & & .11 & & & .20 \\
\hline$R^{2}$ & .08 & .08 & .25 & .14 & .14 & .23 & .06 & .08 & .17 & .07 & .16 & .27 & .25 & .30 & .38 \\
\hline$R^{2}$ increase & .08 & .00 & $.17^{\star \star}$ & $.14^{*}$ & .00 & $.09^{*}$ & .06 & .02 & $.09^{*}$ & .07 & $.09^{\star}$ & $.11^{*}$ & $.25^{\star \star}$ & .05 & $.08^{*}$ \\
\hline
\end{tabular}

NOTE: With the exception of $R^{2}$ and $R^{2}$ increase, all values reflect the standardized regression coefficient when entered into the equation. ${ }^{*} p<.05 .{ }^{* *} p<.01 .{ }^{* * *} p<.001$. 
significant for girls in the bivariate analyses, it was not significant in the multivariate analyses. The addition of the violence variables did not result in a significant change in $R^{2}$ for anxiety, depression, life satisfaction, or selfesteem.

For boys, the significant bivariate relationship between dating violence and anxiety held in the multivariate analyses, and the addition of the three dating violence variables to the model resulted in a significant change in $R^{2}$ of $17 \%(p<.001)$ (see Table 3$)$. The impact of the three dating violence variables on life satisfaction did not hold in the multivariate analyses, but relationships between victimization and posttraumatic stress and depression emerged. The addition of the three dating violence variables to the model resulted in a significant change in $R^{2}$ of $9 \%(p<.05)$ for both (Table 3$)$.

The interpretation of the beta weights for the violence variables may be misleading. Note that the correlations between violence severity and frequency are over .80 (see Table 2), resulting in multicollinearity. The sign for the beta of the frequency variable is negative and the magnitude of the beta is high only because the violence variables are highly intercorrelated (an example of net suppression). When independent variables are highly and positively correlated with each other and with the dependent variable, the most highly correlated variable maintains a positive sign, and the one least highly correlated with the dependent variable has a negative sign (Cohen \& Cohen, 1975).

The relationships of the control variables with the measures of psychological well-being showed few clear patterns. For the boys, social desirability response bias maintained the strongest relationship with well-being among the control variables. For the girls, social desirability was also a strong predictor of well-being. In addition, childhood abuse was significantly related to posttraumatic stress and dissociation in girls, even after controlling for demographics, social desirability, and dating violence.

\section{DISCUSSION}

The results of this study provide preliminary evidence that, for both boys and girls, dating violence victimization is related to reports of lower psychological well-being. For girls, dating violence contributed significantly to posttraumatic stress and dissociation, even when controlling for demographic, family of origin, and social desirability variables. The above result is an important first step in the investigation of posttraumatic stress in adolescent victims of dating violence. We do not know the exact length of time since 
the most recent or severe victimization, but for some respondents it could be several years.

For boys, dating violence contributed significantly to anxiety, depression, and posttraumatic stress. Whereas boys experienced less dating violence overall than girls, those boys who did experience dating violence differed little from girls who experienced dating violence; the boys reported less posttraumatic stress than the girls. Although previous research (Molidor \& Tolman, 1998) suggested that the impact of dating violence might be more severe for girls, that study did not include measures of severity, frequency, and injury.

The numerous significant relations between social desirability and the measures of psychological well-being suggest that the more adolescents wish to provide socially desirable responses, the more likely they are to inflate their self-esteem and life satisfaction scores, and to deflate their posttraumatic stress, dissociation, depression, and anxiety scores. Social desirability was not related to reports of childhood violence or dating violence.

Given that all of the data were collected at the same time point, it is important to be cautious about inferring causality. We assumed that dating violence victimization preceded lower psychological well-being and not the reverse. However, it is possible that low self-esteem or psychological well-being can increase an individual's vulnerability to victimization. Breslau, Davis, Peterson, and Schultz (2000) found that depression increased the risk of traumatic exposure. Additionally, witnessing domestic violence and child abuse can also lead to low self-esteem or lesser psychological well-being, resulting in an increased vulnerability to victimization in a dating relationship.

During adolescence, individuals undergo significant emotional, social, and physical growth and experience many significant events that will help to determine their future paths. Peers and family members often have a profound impact on an adolescent's development and psychological well-being, and they determine the resources available to adolescents that affect adolescent coping strategies. Of particular concern is the possibility that experiencing dating violence as an adolescent may increase the likelihood that an adolescent will continue to experience interpersonal violence in adulthood, either as a victim or perpetrator of domestic violence or as a perpetrator of child abuse in their families of procreation.

As shown by this and other studies (Jackson, 1999; Lewis \& Fremouw, 2001), dating violence among adolescents is a significant social problem. The results of this study indicate that dating violence victimization affects psychological well-being in a variety of ways. If future research confirms the relation between dating violence and psychological well-being, the findings should be used to develop dating violence prevention and intervention programs. 


\section{REFERENCES}

Andrews, F. M., \& Withey, S. B. (1976). Social indicators of well-being: Americans'perceptions of life quality. New York: Plenum Press.

Arias, I., \& Beach, S. R. H. (1987). Validity of self-reports of marital violence. Journal of Family Violence, 2(2), 139-149.

Arias, I., \& Johnson, P. (1989). Evaluations of physical aggression among intimate dyads. Journal of Interpersonal Violence, 4(3), 298-307.

Avery-Leaf, S., Cascardi, M., O’Leary, K. D., \& Cano, A. (1997). Efficacy of a dating violence prevention program on attitudes justifying aggression. Journal of Adolescent Health, 21(1), 11-17.

Bergman, L. (1992). Dating violence among high school students. Social Work, 37(1), 21-27.

Boney-McCoy, S., \& Finkelhor, D. (1995). Psychosocial sequelae of violence victimization in a national youth sample. Journal of Consulting and Clinical Psychology, 63(5), 726-736.

Breslau, N., Davis, G. C., Peterson, E. L., Schultz, L. R. (2000). A second look at comorbidity in victims of trauma: The posttraumatic stress disorder-major depression connection. Biological Psychiatry, 48(9), 902-909.

Briere, J. (1996). Trauma Symptom Checklist for Children (TSCC): Professional manual. Odessa, FL: Psychological Assessment Resources.

Burcky, W., Reuterman, N., \& Kopsky, S. (1988). Dating violence among high school students. The School Counselor, 35, 353-359.

Burke, P. J., Stets, J. E., \& Pirog-Good, M. A. (1989). Gender identity, self-esteem, and physical and sexual abuse in dating relationships. In M. A. Pirog-Good \& J. E. Stets (Eds.), Violence in dating relationships: Emerging social issues (pp. 72-93). New York: Praeger.

Callahan, M. R. (1998). Adolescent dating violence victimization, coping, and psychological well-being [Doctoral dissertation, University of Michigan, 1998]. Dissertation Abstracts International, 59(2-B), 895.

Campbell, A. (1981). The sense of well-being in America: Recent patterns and trends. New York: McGraw-Hill.

Campbell, A., Converse, P. E., \& Rodgers, W. L. (1976). The quality of American life: Perceptions, evaluations, and satisfactions. New York: Russell Sage.

Campbell, J. A., \& Lewandowski, L. A. (1997) Mental and physical health effects of intimate partner violence on women and children. Psychiatric Clinics of North America, 20, 353-374.

Cascardi, M., \& O’Leary, K. D. (1992). Depressive symptomology, self-esteem, and self-blame in battered women. Journal of Family Violence, 7(4), 249-259.

Chodorow, N. (1978). The reproduction of mothering: Psychoanalysis and the sociology of gender. Berkeley, CA: University of California Press.

Cohen, J., \& Cohen, P. (1975). Applied multiple regression/correlation analysis for the behavioral sciences. Hillsdale, NJ: Lawrence Erlbaum.

Crowne, D. P., \& Marlowe, D. (1964). The approval motive: Studies in evaluative dependence. New York: Wiley.

Deal, J. E., \& Wampler, K. S. (1986). Dating violence: The primacy of previous experiences. Journal of Social and Personal Relationships, 3(4), 457-471.

Devito, A. J., \& Kubis, J. F. (1983). Alternate forms of the State-Trait Anxiety Inventory. Educational and Psychological Measurement, 43, 729-734.

Dutton, D. (1992). Empowering and healing the battered woman: A model for assessment and intervention. New York: Springer. 
Fitzpatrick, K. M., \& Boldizar, J. P. (1993). The prevalence and consequences of exposure to violence among African-American youth. Journal of American Academy of Child and Adolescent Psychiatry, 32(2), 424-430.

Follingstad, D. R., Wright, S., Lloyd, S., \& Sebastian, J. A. (1991). Sex differences in motivation and effects in dating violence. Family Relations, 40, 51-57.

Foshee, V. A. (1996). Gender differences in adolescent dating abuse prevalence, types and injuries. Health Education Research, 11(3), 275-286.

Gallers, J., \& Lawrence, K. J. (1991). Overcoming post-traumatic stress disorder in adolescent date rape survivors. In B. Levy (Ed.), Dating violence: Young women in danger (pp. 172183). Seattle: The Seal Press.

Gelles, R. J. (1991). Physical violence, child abuse, and child homicide: A continuum of violence, or distinct behaviors? Human Nature, 2, 59-72.

Graham-Bermann, S. A. (1998). The impact of woman-abuse on children's social development: Research and theoretical perspectives. In G. Holden, R. Geffner, \& E. Jouriles (Eds.), Children exposed to marital violence. New York: APA Books.

Graham-Bermann, S. A., \& Levendosky, A. A. (1998). Traumatic stress symptoms in children of battered women. Journal of Interpersonal Violence, 13(1), 111-128.

Greenwald, H. J., \& Satow, Y. (1970). A short social desirability scale. Psychological Reports, $27,131-135$.

Henton, J., Cate, R., Koval, J., Lloyd, S., \& Christopher, S. (1983). Romance and violence in dating relationships. Journal of Family Issues, 4(3), 467-482.

Holtzworth-Munroe, A., \& Stuart, G. L. (1994). Typologies of male batterers: Three subtypes and the differences among them. Psychological Bulletin, 116, 476-507.

Jackson, S. (1999). Issues in the dating violence research: A review of the literature. Aggression \& Violence Behavior, 4(2), 233-247.

Jezl, D. R., Molidor, C. E., \& Wright, T. L. (1996). Physical, sexual and psychological abuse in high school dating relationships: Prevalence rates and self-esteem issues. Child and Adolescent Social Work Journal, 13(1), 69-87.

Johnson, M. P. (1995). Patriarchal terrorism and common couple violence: Two forms of violence against women. Journal of Marriage and the Family, 57, 283-294.

Kovacs, M. (1992). Children's Depression Inventory. North Tonawanda, NY: Multi-Health Systems.

Levy, B. (1990). Abusive teen dating relationships: An emerging issue for the 90s. Response to the Victimization of Women and Children, 13(1), 59.

Lewis, S., \& Fremouw, W. (2001). Dating violence: A critical review of the literature. Clinical Psychology Review, 21(1), 105-127.

Malik, S., Sorenson, S. B., \& Aneshensel, C. S. (1997). Community and dating violence among adolescents: Perpetration and victimization. Journal of Adolescent Health, 21(5), 291-302.

Miller, J. B. (1991). The development of women's sense of self. In J. V. Jordan, A. G. Kaplan, J. B. Miller, J. L. Surrey, \& I. P. Stiver (Eds.), Women's growth in connection. New York: Guilford.

Mitchell, R., \& Hodson, C. (1983). Coping with domestic violence: Social support and psychological health among battered women. American Journal of Community Psychology, 11(6), 629-654.

Molidor, C., \& Tolman, R. M. (1998). Gender and contextual factors in adolescent dating violence: Gender and contextual issues. Violence Against Women, 4(2), 180-195.

O'Keefe, N. K., Brockopp, K., \& Chew, E. (1986). Teen dating violence. Social Work, 31(6), 465-468. 
O’Leary, K. D. (1999). Psychological abuse: A variable deserving critical attention in domestic violence. Violence and Victims, 14, 3-23.

Orava, T. A., McLeod, P. J., \& Sharpe, D. (1996). Perceptions of control, depressive symptomology, and self-esteem of women in transition from abusive relationships. Journal of Family Violence, 11(2), 167-186.

Reuterman, N. A., \& Burcky, W. D. (1989). Dating violence in high school: A profile of the victims. Psychology: A Journal of Human Behavior, 26(4), 1-9.

Roscoe, B., \& Callahan, J. E. (1985). Adolescents' self-report of violence in families and dating relationships. Adolescence, 20(79), 545-553.

Roscoe, B., \& Kelsey, T. (1986). Dating violence among high school students. Psychology: A Quarterly Journal of Human Behavior, 23(1), 54-57.

Saunders, D.G. (1991). Procedures for adjusting self-reports of violence for social desirability bias. Journal of Interpersonal Violence, 6(3), 336-344.

Singer, M. L., Anglin, T. M., Song, L., \& Lunghofer, L. (1995). Adolescents' exposure to violence and associated symptoms of psychological trauma. Journal of the American Medical Association, 273(6), 477-482.

Spielberger, C. D., Gorusch, R. L., \& Lushene, R. E. (1970). State-Trait Anxiety Inventory manual. Palo Alto, CA: Consulting Psychologist Press.

Stets, J. E., \& Pirog-Good, M. A. (1987). Violence in dating relationships. Social Psychology Quarterly, 50(3), 237-246.

Straus, M. A. (1990a). Injury and frequency of assault and the "representative sample fallacy" in measuring wife beating and child abuse. In M. A. Straus \& R. J. Gelles (Eds.), Physical violence in American families: Risk factors and adaptations to violence in 8,145 families (pp. 75-91). New Brunswick, NJ: Transaction.

Straus, M. A. (1990b). Measuring intrafamily conflict and violence: The Conflict Tactics (CT) Scales. In M. A. Straus \& R. J. Gelles (Eds.), Physical violence in American families: Risk factors and adaptations to violence in 8,145 families (pp. 29-47). New Brunswick, NJ: Transaction.

Straus, M. A., Hamby, S. L., Boney-McCoy, S., \& Sugarman, D. B. (1996). The Revised Conflict Tactics Scales (CTS2): Development and preliminary psychometric data. Journal of Family Issues, 17(3), 283-316.

Michelle R. Callahan, Ph.D., is the founder and principal of $360^{\circ}$ STRATEGIES, an executive coaching and strategic human resources consulting firm. She received her Ph.D. in psychology from the University of Michigan. She has consulted in areas of developmental and organizational psychology for organizations such as J.P. Morgan Chase \& Co., The New York Times, Texaco, Pitney Bowes, Columbia University, and the Executive Leadership Council. She has done extensive research and published in the area of interpersonal violence and women in leadership.

Richard M. Tolman, Ph.D., is an associate professor at the University of Michigan, School of Social Work. He received his Ph.D. from the University of Wisconsin-Madison. He is codirector of the Project for Research on Work, Welfare and Domestic Violence. His current research includes a study of domestic violence and other barriers to work for low-income single mothers. He is on the editorial board of the Journal of Emotional Abuse and was formerly the associate editor of the Journal of Interpersonal Violence. He has served as a domestic violence expert on a number of national panels, including the 
National Institute for Mental Health, the National Institute of Justice, the National Research Council, and the National Women's Resource Center.

Daniel G. Saunders, Ph.D., is an associate professor in the School of Social Work and codirector of the University of Michigan's Interdisciplinary Research Program on Violence Across the Lifespan. He has consulted for the Department of Defense, the National Institute of Justice, and the National Institute of Mental Health. His research on domestic violence focuses on interventions for offenders, the traumatic effects of victimization, and the response of professionals to woman abuse. His professional publications appear in numerous journals and books. 